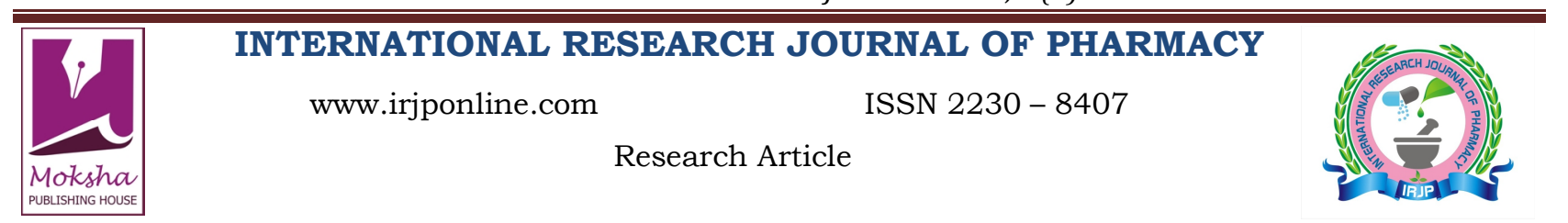

\title{
ASSESSMENT OF THE ACCEPTABILITY OF CONTRACEPTIVE USE AMONG THE WOMEN OF RURAL AND URBAN AREAS OF RAWALPINDI, PAKISTAN
}

\author{
Hina Rehman*, HumeraIshaq, Ammar Hussain \\ Department of Pharmacology, Faculty of Pharmacy, Hamdard University, Karachi, Pakistan \\ *Corresponding Author Email: drhinarehman@hotmail.com
}

Article Received on: 19/03/13 Revised on: 11/04/13 Approved for publication: 01/05/13

DOI: $10.7897 / 2230-8407.04525$

IRJP is an official publication of Moksha Publishing House. Website: www.mokshaph.com

(C) All rights reserved.

\begin{abstract}
Aim of the study was to document the prevalence of use of Contraceptives among the rural and urban areas of Rawalpindi, Pakistan. Specific objectives were to identify the percentage of women using contraceptive, to document different methods used for contraception, to assess the knowledge regarding contraception and to identify the reasons of use and non-use between rural and urban areas of the Rawalpindi, Pakistan. 200females were recruited to assess the use of contraceptives from different rural areas of Kallar Sayedan, and urban areas of Rawalpindi. Questionnaires were filled and data was analysed by SPSS version 19.The $\mathrm{p}$ value was found to be 0.661 for psychological effects. This means that the use of contraceptives is not dependent on psychological effects. The percentage of ease factor among rural area was $12 \%$ and urban area was $26 \%$. The significance for religious factor was checked and the p value was found to be .000 . This means that higher use of contraception was seen in women who considered that there is no religious barrier to contraception. Overall results of this study were found to be $100 \%$.According to the knowledge the concept of contraception was assessed was $93 \%$ in both areas. In which the contraceptive use in urban was $59 \%$ while in rural was $56 \%$.Different methods were used in which high use was IUCD among the other mentioned methods that included pills, injection, tubal legations and others (use of condoms by their husbands), percentage was about $31 \%-25 \%$ in both areas.

Keywords: Acceptability of contraceptives, percentages, Knowledge, Method used for contraception.
\end{abstract}

\section{INTRODUCTION}

The term World Population commonly refers to the total number of living humans on Earth at a given time. In the mid 2012, world population was 7.06 billion. $97 \%$ of which was contributed by developing countries ${ }^{1}$. Developing countries show high birth rates and large number of young population compared to low birth rates and large number of old population in developed countries ${ }^{1}$. It is thought that for the first time in history by the year 2025 deaths will exceed births in developed countries ${ }^{1}$. Population will continue to grow with the addition of one more billion in 3 to 4 years. According to U.N population division this rise in population can be stabilized by 2050 with a lot of hard work ${ }^{2}$. One reason for this rise in the population is thought to be lack of effective contraceptive methods in spite of women wanting to control their family and they want to space births ${ }^{3}$. The decline in growth rate of population will improve the reproductive health and hence improve the quality of life and to achieve this family planning programs have been developed. Family planning is an integral part of daily living and overall health ${ }^{4}$. Family planning allows individuals and couples to attain their desired number of children and the spacing and timing of their births. It is achieved through use of contraceptive methods and the treatment of voluntary infertility. A woman's ability to space and limit her pregnancies has a direct impact on her health and well being as well as on the outcome of each pregnancy ${ }^{5}$. Men and women in Pakistan -especially women are poorly informed about family planning. Contraceptive choices and access to information are limited. $76 \%$ of women are illiterate. Not surprisingly, knowledge about contraception is minimal, and misconceptions abound. Contraceptive use is low, with fewer than $17 \%$ of couples using any modern method ${ }^{6}$.In Pakistan, despite the government program supporting family planning and despite the improvement over the last few decades, total fertility rate remain high (4.8 in 2000) and current contraception use remain relatively low $(20 \% \text { in } 2000)^{7}$.In 2004, Pakistan had lower contraception use than most other
Muslim countries ${ }^{8}$. Fertility and contraception use in developing countries is associated with various markers of socioeconomic status and other related factors 9 . A study conducted by Rob Stephenson, Andy Beke and Delphin Tshibangu revealed that the likelihood of using the pills or a more permanent method rather than injections ${ }^{10}$. In a study conducted in Karachi, Pakistan, according to multivariate analyses, women who were literate, who were of high economic status, family planning, meeting with health worker was likely to use contraceptives as other women ${ }^{11}$.

\section{MATERIALS AND METHODS}

In this study we studied and documented the prevalence of Contraceptive uses in the City of Rawalpindi, Pakistan for identification of percentage of women using contraceptives. To document different methods used for contraception and to assess the knowledge regarding contraception as well as to identify the reasons of use and non-use between rural and urban areas

\section{Study Design}

Cross sectional study in which data was collected in the month of March 2012. This study was conducted in the rural area Kallar Sayedan Rawalpindi and the urban areas of Rawalpindi. Total population of Kallar Sayedan is 1590000 and of Rawalpindi city is 3050000.Literacy rate of Kallar Sayedan is $89 \%$. There are 3 Government hospitals, 17 private clinics in Kallar Sayedan. The number of Basic health unit in Rawalpindi in 98 and 1 family planning centre (Behbood Association of Pakistan).

\section{Tool Development}

The tool used was a Questionnaire. The Questionnaire was developed with the help of existing literature and with a discussion. It had 2 portions. One portion included the demographic knowledge like age, no. of children and marital span. The second portion had 17 closed ended questions which include the option of yes and no. These items were 
categorized in 4 further groups which were use (7 questions), knowledge (2 questions), belief (3 questions) and attitude towards the cost regarding contraceptive use (2 questions) whereas one question was added to know about the professional mostly visited to seek help or opinion regarding its use. After development of questionnaire, academic researchers, patients, doctors, and lady health workers were approached for the face validity. The content validity was done to ensure that the each content is monitoring the factor or not. After validation, field visits were planned for data collection. Female school teachers were also approached for the data collection. Then pilot testing was done to ensure the validity. After pilot testing, modification was done by excluding name and marital status. The tool was developed in

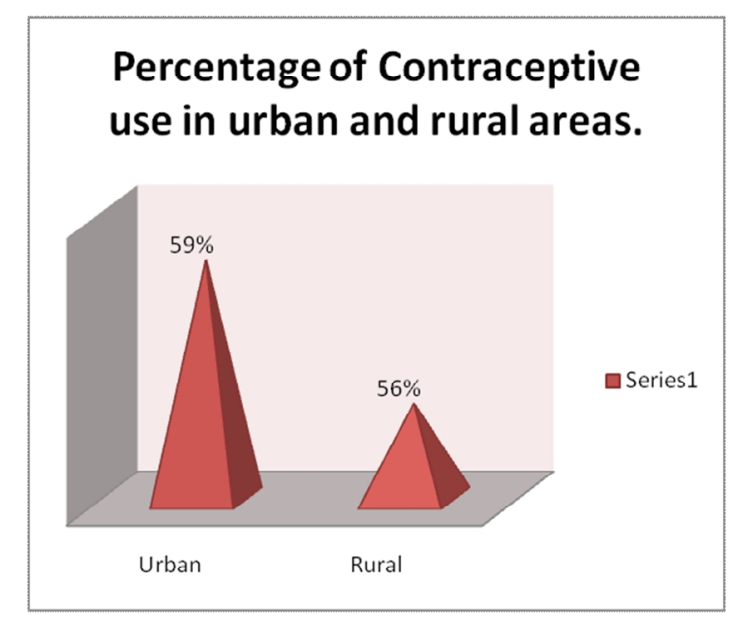

Figure 1: The contraceptive prevalence rate in the urban and the rural women
English but it was implemented in Urdu by translating it in Urdu.

\section{Data Collection}

After collection of data it was analyzed using Chi square test the software SPSS (Version 19). Data was considered significant at $\mathrm{p}<0.05$. Data was entered by making variables. Then data was coded. The codes are as 0 for No, 1 for Yes, 2 for do not know.

\section{Limitations}

The study could have been conducted about the acceptability of use of contraceptives among men and factors affecting their use but due to communication problems it was not feasible.

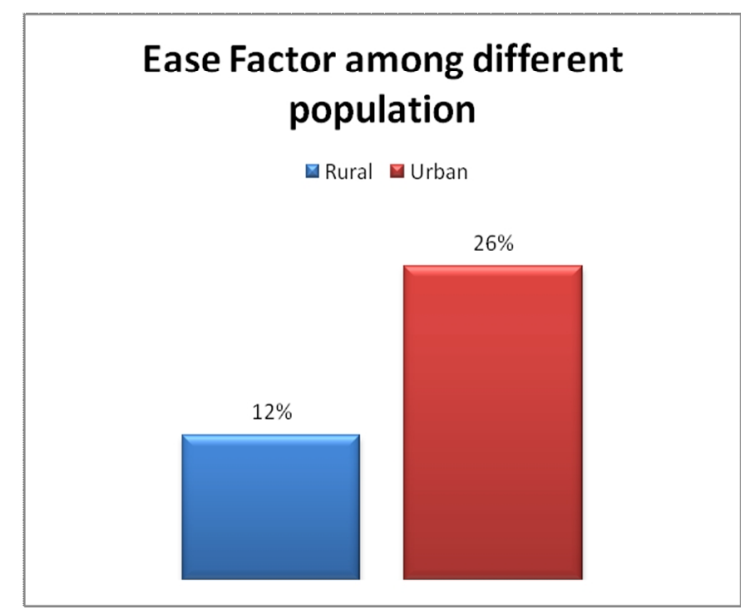

Figure 2: Percentage of women using contraceptives due to ease factor in different populace of Rawalpindi

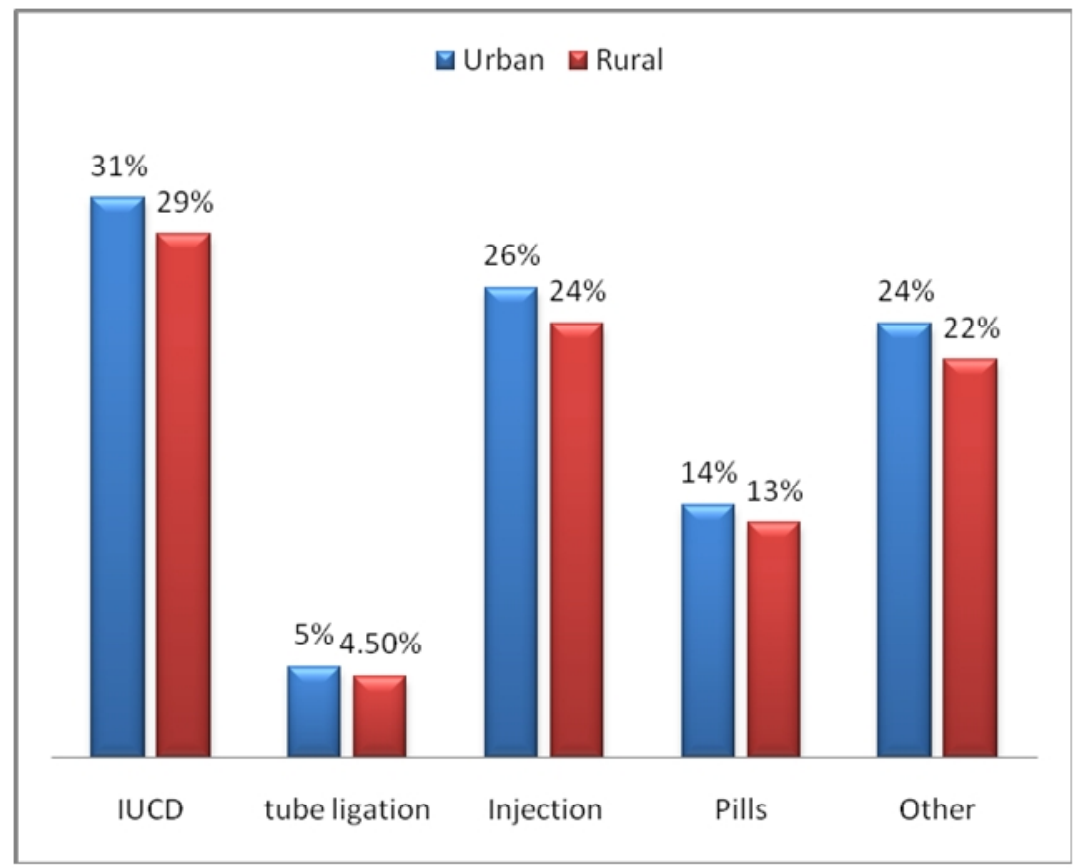

Figure 3: Frequency of use of different methods of Contraception used among rural and urban populace of Rawalpindi (Others refers to Use of Condoms by Husbands of Ladies) 


\section{RESULTS}

Percentages of women using contraceptive in rural and urban area

The response rate of the two hundred respondents overall was found to be $100 \%$. The knowledge which refers to only the concept of contraception was assessed which gave the results i.e. $93 \%$ in both areas. Figure 1 shows the use of contraceptives among rural and urban population of Rawalpindi. Figure 2 shows the ease factor of use of contraceptives which was $12 \%$ in rural population and $26 \%$ in urban population.

\section{Methods used for contraception}

In this study women were asked about the preference of the method used for contraception. The overall results of the different methods used for contraception from two hundred respondents was, use of IUCD (31\%) and then injection $(26 \%)$, pills $(14 \%)$ and tubal ligaton $(5 \%)$ respectively. Any other option (24\%) includes the methods preferred by men like use of condoms. (Figure 3) Use or disuse of contraceptive methods on psychological effects was nonsignificant $(p>0.05)$. Contrastingly religious factor was highly significant regarding use or dis-use of contraception ( $p$ $=0.000$ )

\section{DISCUSSION}

Contraception is the use of artificial or natural means to prevent conception, or pregnancy. Un-intended conception is a very serious issue which results in poor maternal-child health, low birth weight and delayed peri-natal attendance ${ }^{13}$. The project was conducted by selecting convenient houses in the urban and rural areas of Rawalpindi. In the urban area school and hospitals were also included from where the questionnaire was filled by the teachers, lady doctors, and the female patients in the general OPD, data was collected from such places because conducted house hold survey's in urban areas is bit of a difficult task because people are not that much open and welcoming to give their personal information as compare to in rural area where the women are use to in giving such data to different family planning programmes e.g. and are in touch with the local lady health workers regarding the awareness and use of contraception. According to Sathar \& Casterline ${ }^{14}$ fertility transition and use of contraceptive have prevailed after 1990s before which contraception was less than $10 \%$ with 5.3 births per woman in $1996-97^{14}$. Use of contraceptive (primary objective) was found to be a little higher than the rural area. Major reason for this increased use is majorly due to higher literacy in urban women as compared to rural women ${ }^{14}$. Literacy in urban areas has made this program of family planning more successful as compared to rural areas. Here in addition to literacy other factors such as Purdah, threat to izzat and social barriers have made this use of contraception a little bit less than that of urban area. Lady health worker (LHW) program can be more helpful in this regard to decrease these barriers and to overcome the challenges faced by family planning program $^{15}$. On study in rural Punjab mentioned that only one third of women can go to the health centres unescorted ${ }^{16}$. Analysis of percentage of use of different contraceptives (secondary objective of the study) by both urban and rural women was IUCD most probably due to, reversibility, single application and because it is effective for long term birth spacing as its use rise from $4 \%$ in 80 s to $37 \%$ in 2003 in Egypt $^{17}$. Second preferred method is hormone pills. Pills are avoided because it is 28 day packs, with in 21 active pills followed by seven inactive ones (placebo) ${ }^{18}$. None the less these method in spite of their utility are associated with adverse effects like IUDs are associated with serious infections and pills produce headache, breast sores, weight gain, irregular bleeding and depression ${ }^{19}$. Other methods included use of condoms as the third largest determinant. $\operatorname{Agha}^{20}$ in one study states that couple seeking family planning have pressure from in laws. Those men who can talk to their spouse about family planning prefer to use condoms to avoid any ill health to the female $\mathrm{e}^{20}$.

\section{CONCLUSION}

After the completion of analyses and documentation of the results, by keeping in view the objective of the topic we concluded that the percentage of use of contraception is more in the urban areas than in the rural areas. The method used mostly in both the area's is other than the mentioned method's in the tool which intended the male contraception method and in women who uses the contraception, the most preferred and frequently used method is IUCD (Intra uterine Contraceptive device). The reason for the use of IUCD in both the areas is that they think it is convenient to use and there is no discomfort.

\section{ACKNOWLEDGEMENT}

Authors would like to acknowledge Dr.AzharHussain, Director HIPS and his co-worker and Lady health Workers and Ministry of Islamabad, Pakistan.

\section{REFERENCES}

1. Haub C. World population trends 2012. World population data sheet 2012, Population Reference Bureau, USA. Available from http:// www.prb.org/Publications/Datasheets/2012/world-population-datasheet/fact-sheets.aspx ;2013.

2. Ryerson W. Population: An underlying theme in addressing some of the world's most challenging problems. Populatin Media Center. Available form http://www.populationmedia.org/issues/population/?gclid= CMCi4NqWtbcCFQjKtAodaD4AHA; 2009.

3. Gribble JN. Unmet need for family planning. World population data sheet 2012, Population Reference Bureau, USA. Available form http://www.prb.org/Publications/Datasheets/2012/world-populationdata-sheet/fact-sheets.aspx; 2013.

4. World Population Prospects: The 2008 Revision. Population Division of the Department of Economic and Social Affairs of the United Nations Secretariat. June 2009. Retrieved 12 February 2013 Available from https://en.wikipedia.org/wiki/Population_Division_of_the_Department of_Economic_and_Social_Affairs_of_the_United_Nations_Secretariat

5. Family Planning. World Health organization. Last Assessed May 2013. Available from http://www.who.int/topics/family planning/en/

6. Zunia Knowledge exchange last accessed. Available form http://zunia.org/post/greenstar, http://www.psi.org/resources/pubs/gstar1.html; 2013.

7. Castro MT. Women's education and fertility: results from 26 Demographic and Health Surveys. Studies in Family Planning. 1995; 26 : 187-202 http://dx.doi.org/10.2307/2137845

8. Sultan HA, Ahmed MF. Pakistan Reproductive Health and Family planning 2000-2001.Preliminary report of Islamabad, National Institute of population studies; 2001.

9. Population growth and its implications. Islamabad, National Institute of Population studies; 2004-2009.

10. Stephenson R, Beke A, Tshibangu D. Community and health facility influences on contraceptive method choice in the Eastern Cape, South Africa. IntFam Plan Perspect. 2008; 34: 62-70. http://dx.doi.org/ $10.1363 / 3406208$

11. Fikree FF, Khan A, Masood KM, Sajan F, Rahbar. M. Influence contraceptive use among young women in urban squatter settlements of Karachi, Pakistan. International family planning perspectives. 2001; 27(3): 130-136 http://dx.doi.org/10.2307/2673834

12. Bensyl DM, Luliano DA, Carter M, Santelli J, Gilbert BC. Contraceptive Use --- United states and Territories, Behavioural risk factor Surveillance System, 2002. MMWR, Surveillance Summaries 2005; 54 (SS06): 1 - 72. PMid: 16292246

13. Khan A. Mobility of women and access to health and family planning services in Pakistan. Reproductive Health Matters, 1999; 7: 39-48. http: //dx.doi.org/10.1016/S0968-8080(99)90005-8 
14. Sathar ZA, Casterline JB. The onset of fertility transition in Pakistan. Populatin and development review, 1998; 24(4): 773-796. http:// dx.doi.org/10.2307/2808024

15. Sathar Z, Kazi S. Women's autonomy in the context of rural Pakistan. Pakistan Development Reviews, 2000; 39(2): 89-110.

16. Hennick M, Stevenson R, Clements S. Demand for family planning in urban Pakistan. Opportunities and choices working paper No. 2001: 3.

17. Hang R, Montana L, Mishra V. Family planning services quality as a determinant of use of IUD in Egypt. BMC Health Services Research. 2006; 6: 79 http://dx.doi.org/10.1186/1472-6963-6-79 PMid:16792810 PMCid: 1553443

18. Zafar MI. Husband -wife roles as a correlate of contraceptive and fertility behaviour. The Pakistan Development review, 1996; 35(2): 147170
19. Zaki KP, Johnson NE. Does women's literacy affect desired fertility and contraceptive use in rural-urban Pakistan. Journal of biosocial science, 1993; 25: 445-445. http://dx.doi.org/10.1017/S0021932000021829 PMid:8227093

20. Agha S. Intentions to use contraceptives in Pakistan: implications for behaviour change campaigns. BMC Public Health, 2010; 10: 450. http://dx.doi.org/10.1186/1471-2458-10-450PMid:20673374 PMCid:2920282

\section{Cite this article as:}

Hina Rehman, HumeraIshaq, Ammar Hussain. Assessment of the acceptability of contraceptive use among the women of rural and urban areas of Rawalpindi, Pakistan. Int. Res. J. Pharm. 2013; 4(5):124-127 